\title{
El rol de los y las juristas frente a las prisiones y el COVID-19
}

The role of jurists in the face of prisons and COVID-19

\author{
Gabriela Gusis ${ }^{1}$ \\ Universidad de Buenos Aires - Argentina
}

Revista Derechos en Acción ISSN 2525-1678/ e-ISSN 2525-1686

Año 5/No 16 Invierno 2020 (21 junio a 20 septiembre), 603-624

DOl: https://doi.org/10.24215/25251678e436

Recibido: 01/08/2020

Aprobado: 15/09/2020

\section{Introducción}

La realidad de las prisiones de América Latina, y el mundo entero, podríamos afirmar, presentan un escollo ético frente a la propagación de la pandemia en tanto, aunque no todas las prisiones se encuentran en las condiciones de hacinamiento que en gran medida sí hay en América Latina, muchas acarrean problemáticas de híper encarcelamiento, y otras tantas, aunque no cuentan con las mismas condiciones de detención deterioradas como las de nuestros márgenes, llevan consigo los males de cualquier institución total, lo que impone problemas específicos que se evidencian con mayor medida en medio de esta situación, pues la propagación de enfermedades en contextos de encierro estatal resulta ser claramente más alarmante.

Secretaria adscripta de la Asociación Latinoamericana de Derecho Penal y Criminología (ALPEC), Docente de Derecho Penal y Criminología de las Facultades de Derecho de la UBA, UNLP y UNDAV. (ORCID: https://orcid.org/ 0000-0003-3067-7998). 
Sendos estudios han demostrado que las condiciones de encierro propician distintas violencias ${ }^{2} \mathrm{y}$ vulneraciones de derechos fundamentales, entre las que se cuenta el derecho a la salud, mientras el contagio de enfermedades infecto contagiosas en condiciones de prisión -se ha sostenido- aumenta en una proporción que supera con creces las de aquellos que se encuentran en libertad ${ }^{3}$.

El dilema ético es humanitario hoy, y nos impone buscar, analizar y brindar herramientas jurídicas que propicien el sentido humano (de humanitas) del derecho tanto como la prevención de una masacre que parece encaminada en los ámbitos de detención.

\section{Las prisiones argentinas y algunas referencias regionales, en números}

Según Prison Studies ${ }^{4}$, Argentina se encuentra en el $17^{\circ}$ lugar con mayor población penal mundial en números totales, con $103.209^{5}$ personas privadas de libertad a nivel país, superado en la región por Brasil (733.151), México (198.384) y Colombia (122.318).

2 En nuestro medio; Dir. E. R. Zaffaroni: UBACyT, La medida del castigo (2008-2011), la indeterminación (2011-2014) , Dir. Alejandro W. Slokar: UBANEX, Perspectivas de la violencia en prisión (2017-2018), DECyT, Representaciones y perspectivas de la violencia carcelaria". Determinación de las vulnerabilidades. (2018-2020), entre otras.

3 Elías Carranza, ex director ejecutivo de ILANUD, ha presentado trabajos estadísticos que advierten seriamente sobre el incremento exponencial al que la población penal queda sometida en cuestiones de violencia tanto como de posibilidad de contraer enfermedades. La Procuración Penitenciaria de la Nación y la Comisión Provincial por la Memoria, vienen denunciando esta situación hace tiempo, lo que puede verse en los distintos informes anuales disponibles en www.ppn.gov.ar

4 Véase el informe de Prision Studies, disponible en:https://www.prisonstudies.org/ highest-to-lowest/prison-population total/trackback?field_region_taxonomy_tid=All

5 SNEEP, Informe del Sistema Nacional de Estadísticas de Ejecución Penal, elaborado por el Ministerio de Justicia y Derechos Humanos, 2018. Disponible en: http://www.saij.gob.ar/ docs-f/estadisticas-sneep/2018/InformeSNEEPARGENTINA2018.pdf 
Si hablamos en términos de tasas de prisionizados, Argentina posee una tasa de 230 cada 100.000 habitantes ${ }^{6}$, proporción sumamente elevada en relación al resto del mundo. Según el informe del Sistema Nacional de Estadísticas de Ejecución Penal (SNEEP, 2018), Argentina se encuentra en el puesto número $13^{\circ}$ a nivel mundial cuando pensamos en la relación encarceladoshabitantes.

Nuestro país se lleva un puesto diferente si se trata de relacionar población por capacidad de alojamiento. Según el mismo centro referenciado y los datos hasta diciembre de 2018, la tasa de alojamiento superaba en más del $20 \%$ la capacidad declarada por las autoridades para el alojamiento de detenidos ${ }^{7}$.

Con estos números -tan sólo a modo de nuestra- podemos afirmar que Argentina se encuentra en este momento en una situación de sobrepoblación crítica en los términos en los que se evalúa la cuestión a nivel mundial.

No es objeto de este trabajo analizar los múltiples factores que han llevado a que la población encarcelada se elevara durante los últimos años de un modo exponencial en relación al que se venía ya acelerando al menos en los últimos 20 años, pero cabe advertir que en gran medida han influenciado aquel incremento las políticas legislativas que pretendieron restringir derechos y prelibertades durante la ejecución penal, leyes de inexcarcelación por tipos de delito, la ley de flagrancia, entre otras; tanto como las creaciones pretorianas jurisprudenciales del último tiempo que, fuera de los criterios tradicionales para analizar la procedencia de la prisión preventiva, afirmaron la

\footnotetext{
6 El Sistema Nacional informa una tasa de 213.25, pero Prison Studies indica que ello no computa los detenidos en comisarías, que la eleva al número indicado. El propio SNEEP indica una tasa de 232 considerando detenidos en otros espacios no penitenciarios.

7 Según el registro de Prison Studies, se advertía un 122.1\% de ocupación. Cabe advertir que esta ocupación es la declarada por las autoridades, lo que en muchos casos ha sido cuestionado por los organismos de derechos humanos, considerando que esos alojamientos muchas veces son provisorios o no respetan los criterios de estándares internacionales en la materia, por lo que la proporción de sobrepoblación real sería aún más elevada. Véase en: https://www.prisonstudies.org/country/argentina,
} 
necesidad de encarcelar. Han colaborado también, las corrientes punitivistas estimuladas a través de los medios masivos de comunicación, la exposición y persecución pública -incluidos pedidos de juicios políticos- de jueces que resuelven sobre libertades-, y las reacciones públicas de políticos inescrupulosos o temerosos de la opinión pública.

¿Por qué nos interesa relevar estas consideraciones? porque todas las condiciones existentes en las prisiones, ya sean por violencia estructural tanto como por deterioro propio que acarrea la sobrepoblación penal, conllevan como consecuencia el detrimento de las condiciones de detención establecidas constitucional e internacionalmente, vulnerando las mandas constitucionales de los artículos 18 y 75 inc. $22 \mathrm{CN}$ (y sus Tratados).

Esto no es novedoso siquiera en la jurisprudencia de nuestro país, donde los extremos fueron minuciosamente analizados por el más alto Tribunal de la Nación al decidir sobre las prisiones de la Provincia de Buenos Aires, en el famoso fallo "Verbitsky"8

Allí ya se había denunciado que los lugares de alojamiento de detenidos (en ese entonces provinciales) no respetaban las reglas mínimas que garanticen los derechos de los reclusos. Se advertía que los lugares de alojamiento de detenidos debían ser considerados en función a las condiciones de aireación, de iluminación, de calefacción, de sanidad, a la cantidad de camas, de seguridad para el descanso, de contacto diario al aire libre con posibilidad de desplazamiento, de acceso al servicio médico, al sistema educativo, trabajo y a la alimentación adecuada; condiciones éstas, que el Estado provincial no satisfacía siquiera mínimamente en virtud del hacinamiento denunciado, por lo que las condiciones de detención incrementaban las posibilidades de poner en riesgo la vida y la integridad física de las personas, y la posibilidad de contagio de enfermedades infecto-contagiosas tanto de los detenidos como del personal asignado a la custodia.

8 Corte Suprema de Justicia de la Nación, "Verbitsky s/habeas corpus", sentencia del 3 de mayo de 2005. 
En la necesidad de analizar jurídicamente los alcances de la privación de libertad legal y cuáles son condiciones de detención aceptables en el marco de los derechos humanos, consideramos, teniendo en cuenta el sistema de supralegalidad del bloque constitucional analizar los estándares que rigen a nivel internacional e interamericano, urgente pensar posibles soluciones regionales y nacionales desde una hermenéutica que armonice los criterios para aportar al cambio de la realidad carcelaria.

\section{Estándares en materia de privación de libertad, con especial referencia a la posición de garante del Estado y el derecho a la salud}

Los Instrumentos internacionales e interamericanos han desarrollado una serie de principios fundamentales para considerar cuándo las condiciones de detención resultan ser adecuadas y respetuosas de los derechos humanos de las personas privadas de libertad.

Así, son harto conocidas por ejemplo las normas del Pacto Internacional de Derechos Civiles y Políticos, que en su artículo 10 dispone que todas las personas privadas de libertad serán tratadas con humanidad y con respeto a la dignidad inherente de la persona humana. Por su parte el artículo 4 del mismo, establece expresamente algunas disposiciones respecto a las obligaciones de los Estados en materias de derechos humanos, dándoles carácter de normas imperativas de derecho internacional.

En cuanto al derecho a la salud, el Derecho Internacional de los Derechos Humanos considera su más amplio resguardo. Es por ello que cuando una persona se encuentra privada de libertad, el Estado asume el deber de proveer tratamiento médico y de proteger y promover su salud física y mental, así como su bienestar. En ese sentido lo destaca el art. 12 del Pacto Internacional de Derechos Económicos, Sociales y Culturales al reconocer que toda persona tiene esos derechos, incluidos las personas privadas de la libertad, y precisa que para hacerlos 
efectivos los Estados deben tomar medidas en miras de prevenir y tratar las enfermedades epidémicas, endémicas, profesionales y de otra índole, creando condiciones que aseguren la asistencia médica en caso de enfermedad.

Más específicamente, las Reglas Minimas de las Naciones Unidas para el Tratamiento de Reclusos, conocidas como Reglas Nelson Mandela, han dedicado la Regla 24 a la salud, disponiendo realizar exámenes médicos tan a menudo como sea necesario tomando las medidas particular para determinar la existencia de una enfermedad física o mental, tomar en su caso las medidas necesarias; asegurar el aislamiento de los reclusos sospechosos de sufrir enfermedades infecciosas o contagiosas; señalar las deficiencias físicas y mentales que puedan constituir un obstáculo para la readaptación, y determinar la capacidad física de cada recluso para el trabajo".

Por su parte, los Principios básicos para el tratamiento de los reclusos disponen en el apartado $9^{\circ}$ el acceso a los servicios de salud de que disponga el país, sin discriminación por su condición jurídica.

La Observación General $N^{o} 14$ del Consejo Económico $y$ Social define las obligaciones que los Estados Partes deben cumplir a fin a hacer realidad el derecho a la salud en el ámbito nacional. Dable es destacar que la obligación de respetar el derecho a la salud exige que los Estados se abstengan de denegar o limitar la igualdad de acceso de todas las personas, incluso de reos o detenidos, miembros de minorías, solicitantes de asilo e inmigrantes indocumentados, a los servicios de salud que proporcionan cuidados curativos y paliativos, que se abstengan de aplicar prácticas discriminatorias en las políticas de Estado y que se abstengan de imponer medidas discriminatorias en lo tocante al estado de salud y las necesidades de las mujeres.

También resulta medular la Convención contra la Tortura y Otros Tratos o Penas Crueles, Inhumanas o Degradantes, y su protocolo facultativo, en los que se destaca la necesidad de evitar toda pena cruel como principio fundamental de la privación de la libertad. 
En el ámbito interamericano, la carta fundamental tanto como la Convención Americana sobre Derechos Humanos destaca que el Estado es garante por los derechos de las personas privadas de libertad.

Por su parte, el artículo 6 de la Convención Interamericana para Prevenir y Sancionar la Tortura, prohíbe los actos de tortura y los tratos o penas crueles, inhumanos o degradantes, lo que se extiende también al ámbito de las prisiones en donde, como se ha señalado, el rol del estado opera doblemente, por un lado en su posición de garante, y por el otro por las variables y múltiples condiciones de vulnerabilidad y sujeción especial en las que se encuentran los detenidos y detenidas, sin excepción o declaración de emergencia posible.

Los Principios y Buenas Prácticas sobre la Protección de las Personas Privadas de Libertad en las Américas9, establecen en el primero de sus postulados el trato humano y destacan que, en base a la posición especial de garante de los Estados frente a la población penitenciaria, se les respetará y garantizará su vida e integridad personal, sin poder invocarse circunstancias tales como estados de guerra, de excepción, situaciones de emergencia, inestabilidad política interna $u$ otra emergencia nacional o internacional, para evadir el cumplimiento de las obligaciones asumidas.

Este breve e inacabado panorama de los estándares internacionales e interamericanos, y su interpretación al menos por parte del máximo Tribunal regional, nos imponen con carácter de urgencia pensar soluciones jurídicas -además de las que se deben pensar desde la política, que no son objeto de este trabajo- a los problemas acuciantes en medio de esta catástrofe mundial. No asumir la responsabilidad en ese sentido llevaría irremediablemente a ser responsables éticos de la masacre en ciernes.

9 Los Principios y Buenas Prácticas sobre la Protección de las Personas Privadas de Libertad en las Américas, fueron adoptados por la Comisión Interamericana de Derechos Humanos durante el $131^{\circ}$ período ordinario de sesiones, celebrado del 3 al 14 de marzo de 2008. 


\section{Covid-19 La pandemia en la prisión, declaraciones y recomendaciones de los organismos internacionales}

En las últimas semanas son muchos los organismos internacionales que resaltaron el deber de los Estados de proteger la salud física y mental, así como el bienestar de todas las personas bajo su custodia con referencias específicas a la pandemia por COVID-19.

El Subcomité de Prevención de la Tortura y otros Tratos o Penas Crueles, Inhumanos o Degradantes de la ONU ${ }^{10}$, emitió el documento "Recomendaciones del Subcomité de Prevención de la Tortura a los Estados Partes y Mecanismos Nacionales de Prevención relacionados con la pandemia de Coronavirus" que, entre otras cosas, apunta que se tomen medidas para evitar los riesgos asociados a al contagio y al vivir la pandemia en prisión, y recomienda como central reducir las poblaciones penitenciarias.

Las Directrices del Subcomité de Prevención de la Tortura afirman que dado el mayor riesgo de contagio entre las personas en custodia y otros entornos de detención, se insta a todos los Estados a identificar a las personas con mayor riesgo dentro de las poblaciones detenidas; se reduzca las poblaciones penitenciarias siempre que sea posible mediante la implementación de esquemas de liberación temprana, provisional o temporal para aquellos detenidos para quienes sea seguro hacerlo; realizar una evaluación de todos los casos de detención preventiva para determinar si son estrictamente necesarios a la luz de la emergencia de salud pública prevaleciente; evaluar el uso de la detención de migrantes y los campos de refugiados cerrados con el objetivo de reducir sus poblaciones al nivel más bajo posible; considerar la liberación de personas en detención para garantizar que se adopten las medidas adecuadas para aquellos

10 Las recomendaciones fueron adoptadas el 25 de marzo de 2020. Disponibles en: https:// cnpt.gob.ar/recomendaciones-del-subcomite-de-prevencion-de-la-tortura-a-los-estados-partes-y-mecanismos-nacionales-de-prevencion-relacionados-con-la-pandemia-de-coronavirus/ 
que han dado resultado positivo o que son particularmente vulnerables a la infección; asegurar que cualquier restricción a los regímenes existentes se minimice y sea proporcional a la naturaleza de la emergencia de salud y de acuerdo con la ley; garantizar que los mecanismos de queja existentes sigan funcionando y sean efectivos, y asegurar la provisión de suficientes instalaciones y suministros para todos los que permanecen detenidos para permitirles el mismo nivel de higiene personal que debe seguir la población en general.

Las autoridades públicas deberían tomar medidas inmediatas para abordar el hacinamiento en las cárceles, incluidas medidas para respetar la orientación de la OMS sobre el distanciamiento social y otras medidas de salud. Liberación de individuos, incluyendo niños, personas con problemas de salud subyacentes, personas con perfiles de bajo riesgo y que se han comprometido con delitos menores, personas con fechas de liberación inminentes y detenidos por delitos no reconocidos según el derecho internacional, se deben priorizar. La liberación de los niños debe hacerse en consulta y asociación con actores de protección infantil y autoridades gubernamentales relevantes para garantizar una atención adecuada.

En el documento de la Organización Mundial de la Salud ${ }^{11}$ "Preparación, prevención y control de COVID-19 en las cárceles y otros lugares de detención" se establece la probabilidad de que las personas privadas de la libertad sean más vulnerables al brote de la enfermedad por coronavirus (COVID-19) que la población en general debido su condición de vida. La respuesta al COVID- 19 en las cárceles y otros lugares de detención es particularmente desafiante, ya que requiere un enfoque de todo el gobierno y de toda la sociedad, es decir, la salud de la prisión se considera ampliamente como tema de salud pública que debe ser tratada en el marco de los derechos humanos.

11 Documento disponible en: http://www.euro.who.int/en/health-topics/health-determinants/ prisons-and-health/publications/2020/preparedness,-prevention-and-control-of-covid-19-inprisons-and-other-places-of-detention-2020 
La misma organización hace hincapié en el respeto de los derechos de todas las personas afectadas, y señala que todas las medidas de salud pública deben llevarse a cabo sin discriminación de ningún tipo. Las personas en las cárceles y otros lugares de detención no solo son más vulnerables a la infección con COVID 19 sino que también son especialmente vulnerables a las violaciones de los derechos humanos.

Asimismo, aporta pautas para la detección de casos y para el accionar sanitario frente a los mismos siempre señalando que el brote de COVID 19 no debe usarse como una justificación para socavar el cumplimiento de todas las pautas fundamentales incorporadas en las Reglas mínimas de las Naciones Unidas para el tratamiento de los reclusos (las Reglas de Nelson Mandela), entre otros derechos resaltan: Las restricciones nunca deben equivaler a tortura $u$ otro trato o castigo cruel, inhumano o degradante. Prohibición del confinamiento solitario prolongado (es decir, más de 15 días consecutivos). Las decisiones clínicas solo puedan ser tomadas por profesionales de la salud y no deben ser ignoradas o anuladas por personal no médico de la prisión. - Si bien los medios de contacto familiar pueden estar restringidos en circunstancias excepcionales por un período de tiempo limitado, nunca debe prohibirse por completo.

La Alta Comisionada de las Naciones Unidas para los Derechos Humanos ${ }^{12}$, señaló que "las autoridades deberían examinar la manera de poner en libertad a los individuos especialmente vulnerables al COVID-19, entre otros a los presos de más edad y los enfermos, así como a los detenidos menos peligrosos. Además, las autoridades deberían seguir atendiendo las necesidades sanitarias específicas de las mujeres reclusas, incluso de las que están embarazadas, de los internos con discapacidad y los menores de edad".

12 Documento reciente de la Alta Comisionada de Naciones Unidas para los Derechos Humanos, publicación de la delegación para América del Sur, disponible en:Disponible en: https://ohchr.org/SP/NewsEvents/Pages/DisplayNews.aspx?NewsID=25745\&LangID=S 
El documento de la Alta Comisionada de Naciones Unidas regional advierte que: "La urgencia de reducir aún más el hacinamiento en el sistema penitenciario, se ve reforzada por las recientes noticias sobre los primeros casos de contagio por el virus COVID-19 en algunos establecimientos del dicho sistema. El impacto de la suspensión de visitas en lugares de privación de libertad, así como la falta de acceso a la información, están generando reacciones violentas, motines, y riesgos para la seguridad, como resultado de frustración y de un sentimiento generalizado de indefensión de las personas privadas de libertad. La imposibilidad material de implementar las medidas de prevención de contagio -y de cuidado de casos contagiados- en los contextos de encierro penitenciario, sumado al deterioro de la posibilidad de defensa y control judicial por la disminución de las audiencias, activan la responsabilidad de los Estados frente a esta población bajo su custodia, tanto en el caso de la prisión preventiva, como en el de la ejecución de la sentencia privativa de libertad".

A la vez, considera que: "Teniendo en cuenta el cambio radical en las circunstancias, el presente documento aboga por la reducción urgente del número de personas en los centros de detención a través de liberaciones y de la aplicación intensiva de medidas alternativas a la privación de libertad en razón de tres categorías de circunstancias:

a) En primer lugar, los Estados deben evaluar de manera prioritaria la posibilidad de otorgar medidas sustitutivas como los indultos, libertad condicional, arresto domiciliario, libertad anticipada, o cualquier otro régimen que no entrañe reclusión; dando prioridad a las poblaciones con mayor riesgo de salud frente a un eventual contagio del COVID-19, tales como personas mayores, personas con enfermedades crónicas, personas con discapacidad, mujeres embarazadas o con niños a su cargo, y para quienes estén prontas a cumplir condenas. Las medidas excepcionales que se tomen en este contexto no pueden evadir los principios contenidos en las Reglas de Ejecución del Estatuto de Roma para los condenados por delitos de lesa humanidad. 
También se deben considerar urgentemente alternativas a la detención para las personas en prisión preventiva por delitos menores o no violentos, especialmente quienes han sido condenados por delitos relacionados con drogas, así como aquellas personas que entran el sistema penal por primera vez, o que presentan bajo riesgo de fuga y baja peligrosidad para la sociedad.

b) En segundo lugar, las autoridades deben minimizar el riesgo epidemiológico que representan reclusiones parciales o régimen semi-abierto, que permiten cierta libertad de movimiento para personas privadas de libertad y el personal penitenciario. Dada la dificultad de establecer la trazabilidad del coronavirus y alto riesgo de contagio dentro de los lugares de privación de libertad, estas sanciones deberían revocarse y sustituirse urgentemente por liberaciones anticipadas o provisionales, arrestos domiciliarios, fianzas u otras medidas no privativas de libertad.

c) Por último, las condiciones de privación de libertad, tales como el hacinamiento, la falta de higiene, las deficiencias en acceso a los servicios de salud y la mala alimentación, vulneran los derechos de las personas y, además, constituyen factores de alto riesgo para el surgimiento de brotes de la enfermedad. Estas falencias, sumadas a las restricciones de visitas de familiares y de órganos de monitoreo, y limitaciones del acceso a la asistencia letrada en el contexto de COVID-19, pueden equivaler a malos tratos. La liberación urgente de los grupos de personas mencionadas anteriormente aliviaría la carga actual de los lugares de privación de libertad, además de contribuir a la salud pública y a la seguridad comunitaria en el marco de la pandemia."

La Guía de Penal Reform International ${ }^{13}$ refuerza lo anterior con relación al Principio de no dañar. Así, ha estipulado que: "Los sistemas de justicia criminal necesitan tomar medidas para

13 Penal Reform International, Coronavirus. Healthcare and human rights of people in prison, disponible en: http://fileserver.idpc.net/library/FINAL-Briefing-Coronavirus.pdf 
adaptarse a la situación de rápida evolución del COVID-19, reduciendo el número de personas en centros de detención; deben adaptar la manera en la que funcionan para evitar generar daños. De lo contrario, el riesgo es que las personas vulnerables que enfrentan tiempos breves de detención puedan tener consecuencias duraderas y potencialmente irreversibles al estar expuestas al COVID-19."

Con igual preocupación, aparecen las Recomendaciones de la Comisión Interamericana de Derechos Humanos ${ }^{14}$, que urgió a los Estados a garantizar la salud y la integridad de las personas privadas de libertad y sus familias frente a la pandemia del COVID-19 15 .

En el documento, la CIDH subraya las alarmantes condiciones de salubridad e higiene y los niveles de hacinamiento que caracterizan a los establecimientos penitenciarios de la región. En cuanto a la protección de los derechos de las personas privadas de libertad los Estados deben:

1. Adoptar medidas para enfrentar el hacinamiento de las unidades de privación de la libertad, incluida la reevaluación

14 Comisión Interamericana de Derechos Humanos, Comunicado 66/2020, del 31 de marzo. Disponible en: http://www.oas.org/es/cidh/prensa/comunicados/2020/066.asp

15 En ese sentido, establece como prioritario que los Estados adopten medidas que contemplen criterios de excarcelación o alternativas a la privación de la libertad en miras a descongestionar unidades penitenciarias y comisarías. En consonancia con el llamado de la Alta Comisionada de Derechos Humanos de Naciones Unidas del último 25 de marzo, la CIDH exhorta a los Estados a proceder con la debida urgencia para reducir el número de personas privadas de libertad y a examinar los distintos casos para poner en libertad a las personas especialmente vulnerables al COVID-19, en particular a las personas que tienen más edad y aquellas aquejadas por enfermedades. Asimismo, expresa su preocupación por el aumento de la violencia en los centros de privación de la libertad de la región, mencionando los dos motines que tuvieron lugar entre el 23 y 25 de marzo en las cárceles de Coronda y Las Flores, provincia de Santa Fe, en reclamo por las medidas sanitarias adoptadas frente a la pandemia (en los que cinco personas fallecieron y otra decena resultaron heridas). Por otro lado, la CIDH saluda algunas iniciativas que están tomando autoridades de distintos organismos de la región, entre las que menciona el monitoreo y las recomendaciones que viene realizando el Comité Nacional de Prevención de la Tortura de la Argentina (especialmente las publicadas el 20 de marzo) y las solicitudes de medidas como el arresto domiciliario para grupos vulnerables y el uso de conmutación de penas por el Poder Ejecutivo presentadas por el Mecanismo Local de Prevención de la Tortura de la Provincia de Buenos Aires. 
de los casos de prisión preventiva con el fin de identificar aquellos que pueden ser sustituidos por medidas alternativas a la privación de la libertad, dando prioridad a las poblaciones con mayor riesgo de salud frente a un eventual contagio del COVID-19.

2. Evaluar de manera prioritaria la posibilidad de otorgar medidas alternativas como la libertad condicional, arresto domiciliario, o libertad anticipada para personas consideradas en el grupo de riesgo como personas mayores, personas con enfermedades crónicas, mujeres embarazadas o con niños a su cargo y para quienes estén prontas a cumplir condenas.

Más recientemente este documento se vio reforzado en el ámbito interamericano por la Declaración de la Corte Interamericana de Derechos Humanos ${ }^{16}$, en donde advirtió que: "Dado el alto impacto que el COVID-19 pueda tener respecto a las personas privadas de libertad en las prisiones y otros centros de detención y en atención a la posición especial de garante del Estado, se torna necesario reducir los niveles de sobrepoblación $\mathrm{y}$ hacinamiento, y disponer en forma racional y ordenada medidas alternativas a la privación de la libertad"

El Comité Internacional de la Cruz Roja, por otro lado, ha exhortado en un reciente documento titulado: "Recomendaciones para la prevención y control de la COVID-19 en lugares de detención", con fines exclusivamente humanitarios, a una coordinación y articulación entre las instituciones que conforman el sistema de salud y las autoridades responsables de detención, con el fin de elaborar e implementar planes de contingencia para abordar la pandemia de manera integral y oportuna. Asimismo, advierte que lo indicado en el documento debe leerse en consonancia con las disposiciones de la Organización

16 Corte IDH. Declaración de la Corte Interamericana de Derechos Humanos 1/20. COVID-19 y Derechos Humanos: Los problemas y desafíos deben ser abordados con perspectiva de Derechos Humanos y respetando las obligaciones internacionales, 9 de abril de 2020. Disponible en: http://www.corteidh.or.cr/tablas/alerta/comunicado/declaracion_1_20_ESP.pdf 
Mundial de la Salud y su guía más reciente en relación con la preparación, prevención, y control de la COVID-19 en cárceles y otros espacios de detención, y documentos de referencia de entes nacionales rectores en salud.

Por otra parte, pone de resalto y solicita a los operadores judiciales dar trámite prioritario a los casos de personas infectadas con COVID-19, en base a los derechos a la vida, integridad y salud. Así como invocó los correlativos deberes estatales de protección y garantía, y principios como la dignidad humana, la necesidad de la pena o detención provisional, la prohibición de imponer tratos o penas antijurídicas, crueles, inhumanas, o degradantes, el principio de no lesividad y no trascendencia de la pena, así como la prohibición de condiciones incompatibles con la privación de la libertad, y el principio de normalidad según el cual se debe garantizar el acceso a servicios y atención en salud equivalentes con el mundo exterior.

\section{Las penas crueles son penas ilícitas}

La prisión, para ser legal, debe enmarcarse dentro de las reglas del derecho constitucional y el derecho internacional de los derechos humanos, como se ha desarrollado. Cualquier modificación de las condiciones por fuera de la legalildad tornara a la pena ${ }^{17}$ en ilícita.

No es admisible ningún tipo de pena que no respete la dignidad del ser humano como tal, no es posible, por tanto una pena que imponga un dolor más alla de lo legalmente impuesto. En caso de agravamiento de las condiciones de detención, por fuera de ese marco, deberá considerarse a la pena como ilícita.

\footnotetext{
17 Abordaremos el concepto de "pena" en sentido amplio, y definida como un dolor que no resarce, ni restituye, y que constitucionalmente no debe superar la restricción ambultaoria, sin distinguir la prisión preventiva de la pena pues, en los hechos, las manifestaciones de ésta resultan de idénticas consideraciones en la realidad, en función de la reproducción de los mismos efectos deteriorantes. Habrá una pena 0 una prisión preventiva que se tornará en pena ilícita pues resulta de un dolor que supera el consignado por los instrumentos internacionales y constitucionales.
} 
Estas últimas son penas crueles, inhumanas y degradantes, en consideración al derecho constitucional de todos los países latinoamericanos y también por todos los tratados de derecho internacional de derechos humanos.

Debemos considerar que, la actual realidad de las prisiones latinoamericanas están, como se ha señalado, sobrepobladas, y que, en esas condiciones, pasan a ser instituciones que no sólo violan reglas indispensables para garantizar la salud, alimentación, espacios apropiados para el cumplimiento de condiciones de detención, aireación, sino que degradan al máximo la autoestima de los presos, los somete a servidumbre, ponen en peligro su vida en razón de la violencia interna, siendo impotentes para garantizarse su protección tanto como las del personal de seguridad que, cuando existe, lo es en número por completo insuficiente para cumplir esa función elemental ${ }^{18}$.

No es sólo el efecto inevitable deterioro de la institución total $^{19}$. La violencia en las prisiones de la región aumenta en 25 veces las posibilidades de muerte que en el medio libre. Eso significa que en las prisiones se producen más homicidios y suicidios alcanzando límites muy altos en nuestra realidad, hallándose en una situación crítica de muertes violentas.

Tal como señala Zaffaroni, no tiene sentido eludir la realidad con finas especulaciones racionalizadoras, pretendiendo concluir que la tortura infligida por un funcionario estatal a una persona que está sometida o somete a su poder con motivo o pretexto de un delito, no sea una pena. La tortura y en general las penas crueles se ejecutan por funcionarios del Estado sobre personas imputadas o condenadas por delitos, de modo que es una forma clarísima de respuesta estatal a un delito cometido o imputado, o sea, que queda claro que estas penas ilícitas también son penas ${ }^{20}$.

18 Zaffaroni, Penasl ilícitas..., obcit.

19 Erving Goffman, Internados, Ensayos sobre la situación social de los enfermos mentales, Amorrortu, Bs. As., 1994.

20 Zaffaroni, E. R, Las penas crueles son penas... En igual sentido, Penas ilícitas... 
El Estado, como responsable internacional de los compromisos asumidos a través de los tratados internacionales de Derechos Humanos, no puede ampararse en que no se trata de su responsabilidad atribuyéndoselas a los funcionarios individuales. Además, atribuir la responsabilidad a los agentes, o incluso la responsabilidad internacional por las condiciones en las que se ejecutan las penas de prisión no importa negar, que la otra cara de la misma moneda (la otra cara de la responsabilidad) es la cara de quien sufre la prisión en esas condiciones, que pasa a ser víctima de éstas cuando se tornan en ilícitas.

Por tal motivo, resulta un imperativo pensar soluciones jurídicas que den respuesta a este lado de la moneda, pues su omisión también conlleva un trato que supera los límites del Estado de Derecho.

Por ello, la solución jurídica para el caso del agravamiento debe importar -por un lado del análisis- indefectiblemente una consecuencia jurídico penal, no sólo en la sanción administrativa y/o penal para quienes la agraven, tanto como para el Estado como garante, sino además -del lado opuesto, como se ha dichoen una compensación judicial de pena para quien la sufra ${ }^{21}, \mathrm{y}$ una de esas alternativas, resulta en la posible compensación por

21 Al margen de este ejercicio ilícito letal del poder punitivo -y pese a la ratificación de tratados internacionales- abundan en la región las denuncias de delitos de torturas, malos tratos, lesiones o sufrimientos impuestos por funcionarios o no evitados por ellos, en especial a personas privadas de libertad o en el acto de hacerlo, como también las víctimas de motines, violencias o tumultos carcelarios y enfermedades contraídas y lesiones sufridas como resultado de deficientes condiciones prisionales, presos en dependencias policiales, lesiones en traslados y circunstancias análogas.

Zaffaroni señala que casi todas estas lesiones a bienes jurídicos son producto de conductas típicas (activas u omisivas) de funcionarios estatales, aunque algunas los sean por negligencia o por circunstancias no imputables a los funcionarios de las agencias ejecutivas, sino del deficiente material de que estos funcionarios disponen o de las precarias condiciones en que deben cumplir sus tareas. De toda forma, en el plano internacional se trata de violaciones a los derechos humanos que generan responsabilidad de los Estados, como lo prueban numerosas sentencias del sistema regional de derechos humanos.

Cuando estas lesiones configuran conductas típicas de los funcionarios, en gran medida resultan impunes, dada la dificultad para su investigación o la poca o nula atención que le dispensan los tribunales abarrotados de causas por hechos de menor gravedad, como 
tiempo de prisión ilícita ${ }^{22}$, descontando o compensado con una reducción -o incluso cancelación, según la gravedad del daño sufrido- de la pena lícita que se le imponga o que deba cumplir o le reste por cumplir, según el caso.

En la doctrina penal tampoco es algo nuevo. Ya hace tiempo Zaffaroni ha analizado estas situaciones afirmando que cuando una pena comienza siendo lícita pero se torna ilícita en su transcurso derivado del agravamiento de las condiciones de detención, es el judicial que a través de su respuesta jurídica puede reevaluar las condiciones de cumplimiento de la ejecución de la pena con el fin de compensar los tratos ilícitos que se susciten en la pena lícita en función del principio de proporcionalidad, de doble punición, y el fin constitucional de la ejecución penal.

En el último trabajo sobre la cuestión, Zaffaroni ${ }^{23}$ afirmó que "la ciencia jurídica no es omnipotente- se le impone como mandato ético sumarse al esfuerzo de contención. La ciencia jurídico penal debe proporcionar una respuesta a los interrogantes que su práctica le plantea, especialmente en las cuestiones cruciales que hasta el presente no ha enfrentado con decisión, como es el problema de las penas ilícitas”. Cuál es el camino entonces que debe seguir el discurso jurídico en tanto contentos de irracionalidades?

\section{El rol fundamental de la judicatura}

La obligación de respetar el derecho a la salud exige que los Estados, y sus poderes, cumplan de manera urgente con la necesidad que imponen los tiempos, cual es una razón

también por la falta de denuncia, ante la amenaza de represalias por parte de los mismos funcionarios o de sus agencias.

22 Se han elaborado desde distintas perspectivas posibilidades de compensaciones económicas, adelantamiento de institutos de pre libertades, incluso en casos conmutaciones de penas. Proponemos una compensación temporal debido a la consideración, que se explicará más adelante, sobre la importancia del tiempo vivencial, aún mas en la prisión.

23 Zaffaroni, E.R, Penas ilícitas y dogmática penal, Ediciones del Sur, Buenos Aires, 2020. 
eminentemente humanitaria, en medio de la pandemia por el Covid-19. En el caso del poder judicial ello importa un compromiso efectivo que debe quedar plasmado en las sentencias, las cuales deben dictarse -en la actual crisis de salud mundial- sin la menor dilación, pues cada vida es única e irremplazable, y no es aceptable ni jerarquizar ni desvalorizar siquiera una sola vida humana. En los últimos meses hemos presenciado, y aún seguimos haciéndolo, que en las instituciones masivas de encierro el poder de letalidad de la enfermedad SARS-COVID 19 es inmensa y se propaga rápidamente. Ha pasado en geriátricos, en hospitales. Si pensamos que nuestras prisiones no respetan mínimos de metraje por persona, condiciones de higiene y salubridad mínimas, qué sucederá entonces cuando ingrese el virus?.

Posiblemente la masacre por goteo -término desarrollado por E. R. Zaffaroni, por el cual se expone la existencia de muertes lentas y continuas por parte del sistema penal no llegando a visibilizarse exponencialmente de forma masiva e indiscriminada, pero que conlleva en definitiva a ese resultado-, se visibiliza dentro de las prisiones acorde a la realidad que hemos descripto, en momentos en que ingrese el virus será de muerte masiva e imparable, más allá de los intentos por cumplir con protocolos que con suerte se han cumplido en condiciones completamente disímiles a nivel mundial (separación y aislamiento de posibles infectados, tratamiento adecuado de salud, condiciones de preservación y cuidado del personal de salud para evitar el contagio y propagación, elementos de higiene, etc.).

Como hemos dicho, esta forma de morir bajo la responsabilidad estatal ya sucede en las prisiones de nuestra región, pero visto como se van sucediendo a nivel mundial las cosas, se incrementan mucho más las posibilidades de muerte en situaciones como la actual pandemia en el caso de los detenidos y detenidas. Por ello, nos preguntamos si esa masacre que produce el sistema penal no dejará de ser por goteo para transformarse en muertes a chorros producidas bajo la responsabilidad del Estado. 
Entendemos que el rol de la judicatura, como control de desboques del poder punitivo tanto como de la realización y el respeto de los derechos y las garantías de los individuos, debe asumir en medio de estas circunstancias un papel primordial. Ello no sólo por ser uno de los poderes del Estado, y por tanto obligado a ello, sino también por un resguardo ético de la dignidad de todo ser humano.

La sobrepoblación penal y la situación de la pandemia es un problema político para la administración (poder ejecutivo) y también para los legisladores, pero cuando éstos hacen caso omiso del deterioro carcelario, son los jueces quienes deben buscar las vías de solución resolver o al menos mitigar el dolor de una prisión que se torna en un peligro real y concreto de masacre. El rol de la judicatura tiene en sus manos, como poder del Estado, una parte esencial de responsabilidad tanto como de capacidad de resolución con el objeto de evitar que las prisiones se tornen en penas de ilicitud manifiesta. Es en ese sentido que el saber jurídico de contención penal asume una doble oportunidad de servir como apédice constitucional e internacional de los derechos humanos. El poder jurídico cobra una verdadera significación en la realización del Estado de Derecho.

En este contexto que resurge la necesidad de pensar al saber jurídico como contención del poder punitivo por parte de los jueces, en tanto el saber penal (el discurso de los juristas) asignando una función interpretativa de las leyes penales en clave de los derechos humanos y afianzar el Estado de derecho.

No por obvio vale recordar que hace ya casi doscientos años el maestro de Pisa, Francesco Carrara, denunciaba al derecho penal que se limitaba a racionalizar cualquier decisión del poder llamándolo la schifosa scienza ${ }^{24}$ porque su función no es legitimar las decisiones del poder sino limitarlo.

Si bien dicho contexto situacional exige el mayor esfuerzo creativo por parte de las agencias políticas y judiciales para

24 Carrara, Francisco, Vicisitudes del fundamento del derecho de castigar, en "Opúsculos de Derecho Criminal", Vol. I, Bogotá, 2000, p. 143. 
evitar que el fenómeno continúe robusteciéndose, la positivización internacional de los derechos humanos suministran una importante herramienta para que la judicatura (agencia judicial) pueda llevar a cabo una teleología reductora del poder punitivo, reduciendo así las expresiones máximas del estado de policía que late en nuestras democracias.

La labor jurídica aparece llamada a efectuar un reclamo para que las distintas agencias del sistema penal respondan al interrogante de la dirección que va a seguir la política penitenciaria actual ante la considerable tasa actual de encarcelamiento y el Covid, y sobre todo, se haga cargo del nada auspicioso destino inmediato y mediato de las personas prisionizadas, tal como señala Zaffaroni.

Volvamos entonces a los instrumentos internacionales y las recomendaciones que, en torno al coronavirus se han emitido desde prácticamente todos los organismos internacionales. La obligación de los Estados de respetar el derecho a la salud de todas las personas, pero más de aquellas sobre las que el estado tiene una especial función de garante, como en el caso de las personas prisionizadas, exige que los Estados, y sus poderes, cumplan de manera urgente con la necesidad que imponen los tiempos, cual es una razón eminentemente humanitaria.

En el caso del poder judicial ello importa un compromiso efectivo que debe quedar plasmado en las sentencias, las cuales deben dictarse en la emergencia sin la menor dilación, pues cada vida es única e irremplazable, y no es aceptable ni jerarquizar ni desvalorizar siquiera una sola vida humana.

Quien salva una vida salva el mundo dice el Talmud, no seamos cómplices silenciosos de las muertes que genera esta masacre que ya no es por goteo sino en cataratas.

\section{Bibliografía}

Carrara, Francisco (2000) "Vicisitudes del fundamento del derecho de castigar" en Opúsculos de Derecho Criminal. № 1 . Bogotá 
Comisión Interamericana de Derechos Humanos (2020) Comunicado 66/2020. En línea en: http://www.oas.org/es/cidh/ prensa/comunicados/2020/066.asp

Corte Suprema de Justicia de la Nación (2005) "Verbitsky s/habeas corpus". Sentencia. En línea en: http://www.saij.gob.ar/ corte-suprema-justicia-nacion-federal-ciudad-autonomabuenos-aires-verbitsky-horacio-habeas-corpus-fa050003192005-05-03/123456789-913-0005-0ots-eupmocsollaf

Goffman, Erving (1994) Internados, Ensayos sobre la situación social de los enfermos mentales. Editorial Amorrortu. Buenos Aires.

Penal Reform International (2020) Coronavirus. Healthcare and human rights of people in prison. En línea en: http://fileserver. idpc.net/library/FINAL-Briefing-Coronavirus.pdf

World Prision Brief (2020) Stadistical Prision Studies. En línea en en:https://www.prisonstudies.org/highest-to-lowest/prisonpopulation total/trackback?field_region_taxonomy_tid=All

SNEEP -Sistema Nacional de Estadísticas de Ejecución Penal- (2018). Informe Anual. En línea en: http://www.saij.gob.ar/docs-f/ estadisticas-sneep/2018/InformeSNEEPARGENTINA2018.pdf

UBANEX (2018) "Perspectivas de la violencia en prisión" en DECyT, Representaciones y perspectivas de la violencia carcelaria. Determinación de las vulnerabilidades (2018-2020)

Zaffaroni, Eugenio Raúl (2008) La medida del castigo. El deber de compensación por penas ilegales. Editorial Ediar. Buenos Aires

- (2020) Penas ilícitas y dogmática penal. Ediciones del Sur. Buenos Aires. 